\title{
Appendix Hyperplastic Polyp
}

National Cancer Institute

\section{Source}

National Cancer Institute. Appendix Hyperplastic Polyp. NCI Thesaurus. Code $C 96416$.

A non-neoplastic polyp that arises from the appendix. It is characterized by the presence

of elong ated serrated crypts and the absence of atypia or dysplasia. 